Jap. J. Pharmacol. 17, 199-207 (1967)

\title{
STIMULATORY EFFEGT OF ADENOSINE TRIPHOSPHATE AND MAGNESIUM ON THE RELEASE OF CATEGHOL- AMINES FROM ADRENAL MEDULLARY GRANULES
}

\author{
MOTOO OKA, TAKESHI OHUCHI, HIROSHI YOSHIDA* \\ AND REIJI IMAIZUMI \\ Department of Pharmacology, Faculty of Medicine, Osaka University, Kita-ku, Osaka \\ Received for publication October 25, 1966
}

It is well known that catecholamine is stored within specific granules in various tissues and when it is released from these granules it displays its physiological effects. Therefore, the mechanisms of storage and release of catecholamine have recently become a topic of interest.

It was reported by Kirshner (1) and Carlsson et al. (2) that the uptake of ${ }^{14} \mathrm{C}$-catecholamine into the granules of the adrenal medulla was stimulated by ATP and $\mathrm{Mg}^{2+}$. Euler and Lishajko also showed ATP- $\mathrm{Mg}^{2+}$ dependent uptake of catecholamine by the granules of adrenergic nerves $(3,4)$.

The effect of ATP and $\mathrm{Mg}^{2+}$ on the uptake and release of catecholamine in the granules of adrenal medulla was also studied in this laboratory. It was found that on the addition of ATP and $\mathrm{Mg}^{2+}$, there was only slight or no inhibition of the release of catecholamine from the granules when they were incubated in sucrose solution, while when they were incubated in saline solution catecholamine release was greatly stimulated.

This report gives further details of the stimulatory effect of ATP and $\mathrm{Mg}^{2+}$ on the release of catecholamine from the granules of adrenal medulla. A preliminary report of this work has been published $(5,6)$.

\section{METHODS}

\section{Preparation of adrenal medullary granules}

Granules of bovine adrenal medulla were prepared essentially as described by Hillarp (7) and Kirshner (8). The medulla $(5-10 \mathrm{~g})$ was homogenized with a Potter glass homogenizer in 5 to 6 volumes of ice cold $0.3 \mathrm{~m}$ sucrose (or $154 \mathrm{~mm} \mathrm{NaCl}-5 \mathrm{~mm} \mathrm{KCl}$ ) containing 40 mм Tris buffer, $\mathrm{pH} 7.3$. Coarse material was removed by centrifugation at $1,000 \times g$ for 10 minutes. The supernatant was centrifuged at $20,000 \times g$ for 15 minutes. The supernatant was decanted and the upper layer of the sediment fraction was removed by carefully swirling the tube after addition of $0.3 \mathrm{M}$ sucrose (or $154 \mathrm{~mm} \mathrm{NaCl-5} \mathrm{mm} \mathrm{KCl}$ ). The sediment was washed twice with $0.3 \mathrm{~m}$ sucrose (or $154 \mathrm{~mm} \mathrm{NaCl-5} \mathrm{mm} \mathrm{KCl}$ ) in the same way.

岡 源郎・大内 武・吉田 博・今泉 礼治

* Present address: Department of Neuropharmacology and Neurochemistry, Institute of Higher Nervous Activity, Faculty of Medicine, Osaka University, Osaka. 
This sediment was finally suspended in a solution of $0.3 \mathrm{~m}$ sucrose or $154 \mathrm{~mm} \mathrm{NaCl-5} \mathrm{mm}$ $\mathrm{KCl}$, and was used as the granule preparation.

In some experiments, in order to prepare granules which were not appreciably contaminated with mitochondria, membrane filter techniques were applied, as described in our previous paper (9). The supernatant fraction from which coarse material had been removed by centrifugation was passed successively through membrane filters of $1.2,0.65$, $0.45,0.3,0.22 \mu$ pore size. The fraction passing through the $0.3 \mu$ or $0.22 \mu$ pore size membrane filter was centrifuged at $10.000 \times g$ for 30 minutes. The sediment was washed with $0.3 \mathrm{~m}$ sucrose or $154 \mathrm{~mm} \mathrm{NaCl-5} \mathrm{mM} \mathrm{KCl}$, and finally suspended in a solution of $0.3 \mathrm{~m}$ sucrose or $154 \mathrm{~mm} \mathrm{NaCl}-5 \mathrm{~mm} \mathrm{KCl}$. These granules were shown to be practically free from mitochondria.

\section{General procedure}

Incubations were carried out in plastic centrifuge tubes without shaking as noted in the accompanying tables and figures. At the end of the incubation period the centrifuge tubes were immediately placed in ice, and then centrifuged at $20,000 \times g$ for 15 minutes. Catecholamine in the sediment and supernatant was extracted by $0.4 \mathrm{~N}$ perchloric acid and determined fluorometrically by the ethylenediamine condensation method $(10)$.

\section{Uptake of ${ }^{14} \mathrm{C}$-adrenaline into the granules}

Adrenaline- $7-{ }^{14} \mathrm{C}$ was used in this experiments. The conditions used in each incubation are given in the table. After incubation, the redioactivity in the sediment was extracted by $0.4 \mathrm{~N}$ perchloric acid and measured in a Tri-Carb liquid scintillation counter.

\section{Measurement of structural changes in the granules}

To study the structural changes in the granules, the changes of optical density at 520 $\mathrm{m} \mu$ of suspensions of granules were examined. Suspensions of granules separated by the membrane filter technique were added to test medium, usually $154 \mathrm{~mm} \mathrm{NaCl-5} \mathrm{mm}$ $\mathrm{KCl}-80 \mathrm{~mm}$ Tris buffer, $\mathrm{pH}$ 7.3, to produce an initial optical dencity of between 0.45 and 0.60 at $520 \mathrm{~m} \mu$. The experiments were carried out in a Beckman DU type-Shimazu spectrophotometer as described in the footnotes of the figures.

\section{RESULTS}

\section{I) Stimulation of catecholamine release by $\mathrm{ATP}$ and $\mathrm{Mg}^{2+}$}

As shown in Fig. 1, on addition of ATP there was little or no, inhibition of the release of catecholamine from the granules when they were incubated in sucrose solution. The further addition of $\mathrm{Mg}^{2+}$ to this system also caused little or no, inhibition of the release. However, the rate of release of catecholamine from granules incubated in $154 \mathrm{~mm} \mathrm{NaCl-5}$ $\mathrm{mm} \mathrm{KCl}$ solution was greatly stimulated by the addition of ATP together with $\mathrm{Mg}^{2+}$. Neither ATP nor $\mathrm{Mg}^{2+}$ alone had any effect on the release of catecholamine. $\mathrm{Mg}^{2+}$ could not be replaced by $\mathrm{Ca}^{2+}$. Fruthermore, $\mathrm{Ca}^{2+}$, which by itself caused marked release of catecholamine from the granules, was shown to be inhibitory in the presence of ATP and $\mathrm{Mg}^{2+}$. Replacement of the medium containing $154 \mathrm{~mm} \mathrm{NaCl}-5 \mathrm{~mm} \mathrm{KCl}$ by one containing 


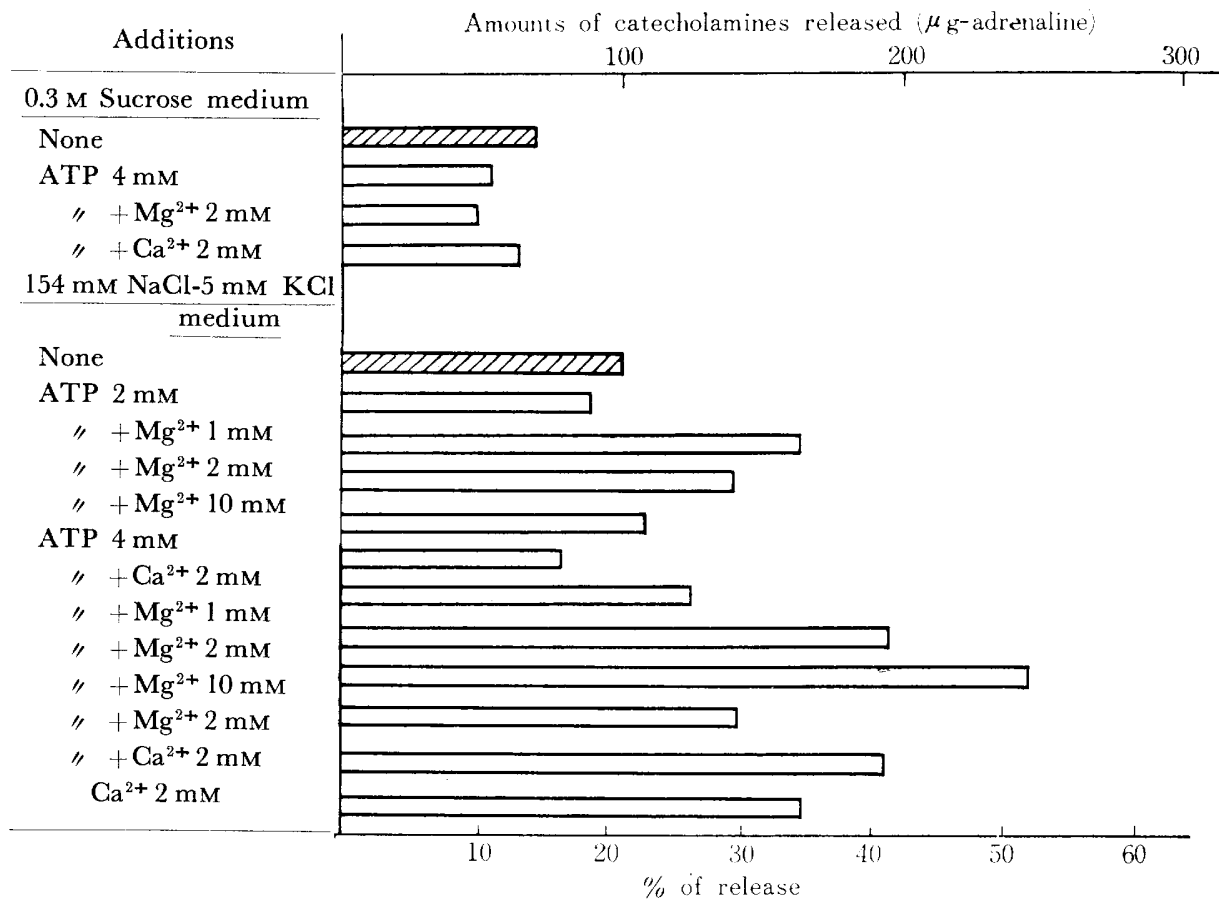

FIG. 1. Release of catecholamines from adrenal medullary granules. Each vessel contained, in a final volume of $3 \mathrm{ml}$ : granules, $420-500 \mu \mathrm{g}$ catecholamines ; 80 $\mathrm{mM}$ Tris buffer ( $\mathrm{pH} 7.3$ ) ; $0.3 \mathrm{M}$ sucrose or $154 \mathrm{mM} \mathrm{NaCl-5mM} \mathrm{KCI.} \mathrm{Incubations}$ were carried out in air for 15 minutes at $37^{\circ} \mathrm{C}$. After incubation, the catecholamines in the granules and in the supernatants were extracted with $0.4 \mathrm{~N}$ perchloric acid and estimated fluorometrically by the ethylenediamine condensation method (10). Each value is the mean of 3-10 experiments. The standard deviation was within 10 per cent.

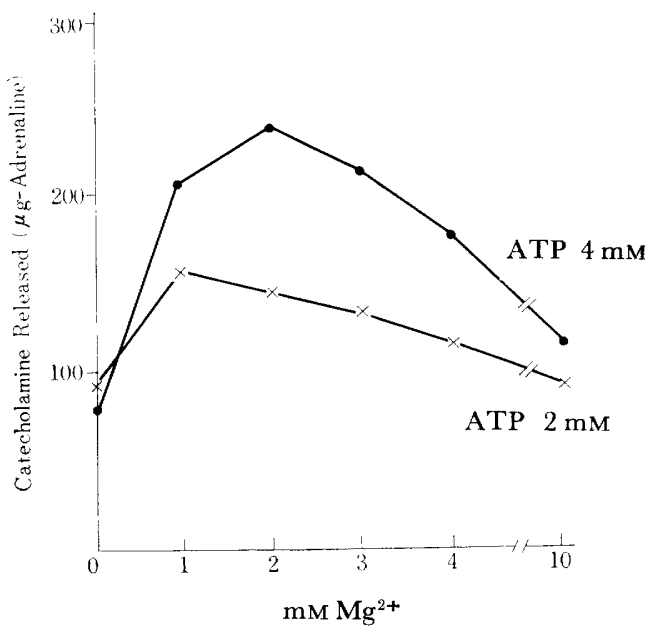

FIG. 2. Effect of magnesium concentration on release of catecholamine. Conditions as in Fig. 1. Incubation, 15 minutes.
$154 \mathrm{~mm} \mathrm{KCl-5} \mathrm{mm} \mathrm{NaCl}$ did not affect the rate of $\mathrm{ATP}-\mathrm{Mg}^{2+}$ stimulated catecholamine release.

As shown in Figs. 1 and 2, the stimulation of catecholamine release by ATP and $\mathrm{Mg}^{2+}$ was found to depend on the molar ratio of ATP to $\mathrm{Mg}^{2+}$. When $2 \mathrm{~mm}$ ATP was used, $1 \mathrm{~mm} \mathrm{Mg}^{2+}$ was necessary for maximum stimulation of the release of catecholamine. Similarly with $4 \mathrm{~mm}$ ATP, 2 $\mathrm{mm} \mathrm{Mg}^{2+}$ was required. Therefore, the molar ratio of $\mathrm{ATP}$ to $\mathrm{Mg}^{2+}$ required for maximum release was thought to be about 2: 1 . 
2) Release of catecholamine as a function of time

Fig. 3 shows the release of catecholamine from the granules as a function of time in the presence and absence of ATP and $\mathrm{Mg}^{2+}$. There was a rapid initial release followed by a much slower release of catecholamine in the presence of ATP and $\mathrm{Mg}^{2+}$. The catecholamine release from the granules did not occur at $0^{\circ}-4^{\circ} \mathrm{C}$ either in the presence or absence of ATP and $\mathrm{Mg}^{2+}$.

3) Influence of various buffers on the release of catecholamine

ATP and $\mathrm{Mg}^{2+}$ caused stimulation of catecholamine in Tris or glycylglycine buffer,

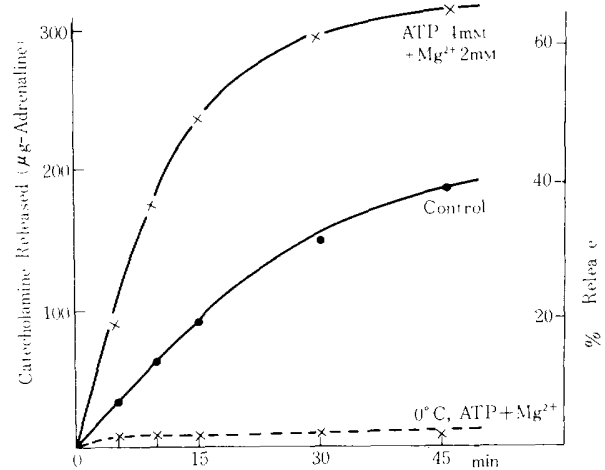

FIG. 3. Release of catecholamine as a function of time. Composition of incubation medium as in Fig. 1.

(Fig 4). However, the stimulatory effect of $\mathrm{ATP}$ and $\mathrm{Mg}^{2+}$ was much less in phosphate buffer.

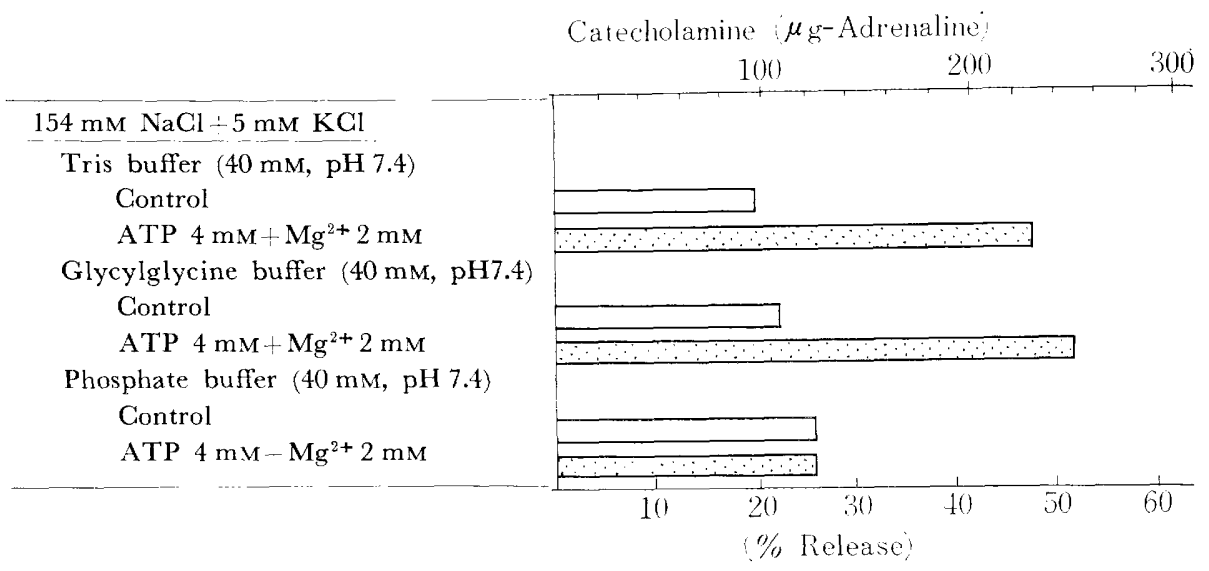

FIG. 4. Effect of ATP-Mg $\mathrm{Mg}^{2+}$ on release of catecholamine in various buffers. Incubation, 15 minutes $37 \mathrm{C}$. Conditions of incubation as in Fig. 1.

\section{4) Nucleotide specificity}

As shown in Fig. 5, ADP, AMP or adenosine at concentrations at which ATP caused stimulation were ineffective in stimulating release of catecholamine.

5) Stimulation of catecholamine uptake by $\mathrm{ATP}$ and $\mathrm{Mg}^{2+}$

As shown in Table 1, the uptake of ${ }^{14} \mathrm{C}$-adrenaline into granules incubated in sucrose solution was greatly stimulated by the addition of ATP and $\mathrm{Mg}^{2+}$. Under these conditions, the release of catecholamine from the granules was not stimulated, as shown in Fig. 1. When the granules were incubated in $154 \mathrm{~mm} \mathrm{NaCl-5} \mathrm{mm} \mathrm{KCl}$ solution, the release of endogenous catecholamine was greatly stimulated by ATP and $\mathrm{Mg}^{2+}$ (Figs. 1 and 2) 


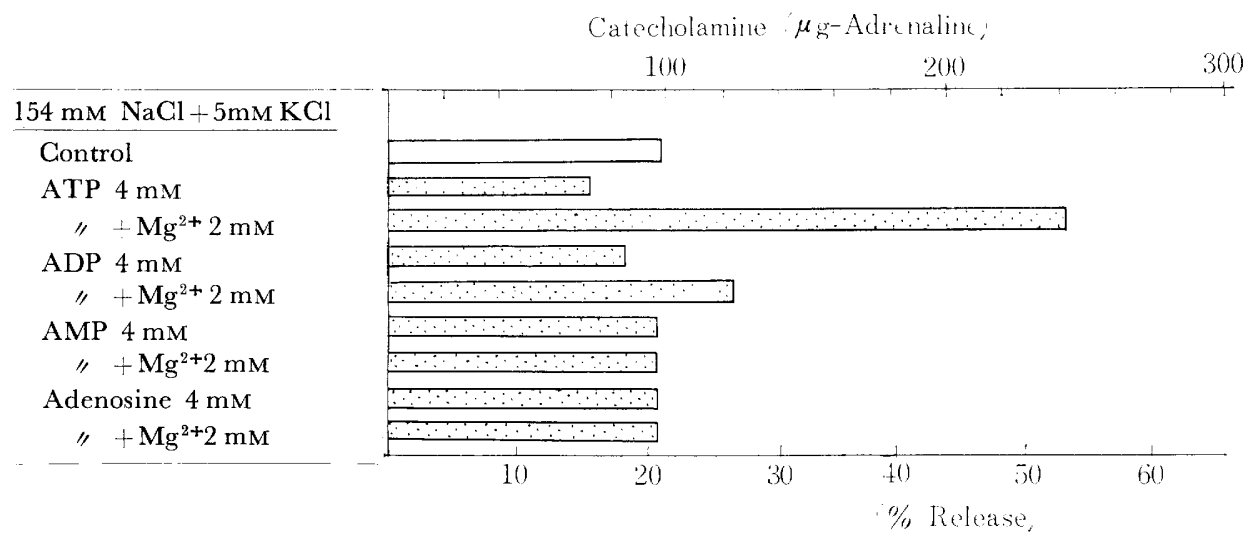

Fig. 5. Effect of adenosine phosphate and magnesium on catecholamine release from adrenal medullary granules.

Incubation, 15 minutes $37^{\circ} \mathrm{C}$. Composition of the incubation medium as in Fig. 1.

TABLE 1. Effect of $\mathrm{ATP}$ and $\mathrm{Mg}^{2+}$ on uptake of

${ }^{14} \mathrm{C}$-adrenaline into the granules.

Each vessel contained, in a final volume of $3 \mathrm{ml}$; granules $420-500 \mu \mathrm{g}$ catecholamines ; 80

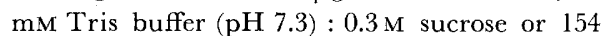
$\mathrm{mM} \mathrm{NaCl-5} \mathrm{mM} \mathrm{KCl} ; d l$-adrenaline- $7-{ }^{14} \mathrm{C}(2.5$ $\mu \mathrm{c}, 17.5 \mu \mathrm{g})$; Incubations were carried out in air for 15 minutes at $37^{\circ} \mathrm{C}$. Each value is the mean of five experiments. The standard deviation was within 10 per cent.

\begin{tabular}{c|c}
\hline & $\begin{array}{c}{ }^{14} \mathrm{C} \text {-adrenaline uptake } \\
\text { (c.p.m.) }\end{array}$ \\
\hline 0.3 M Sucrose & 22,200 \\
Control & 20,020 \\
ATP 4 mM & 97,290 \\
" $+\mathrm{Mg} 2 \mathrm{mM}$ & 21,070 \\
" $+\mathrm{Ca} 2 \mathrm{mM}$ & \\
$154 \mathrm{mM} \mathrm{NaCl}+5 \mathrm{~mm} \mathrm{KCl}$ & 21,150 \\
Control & 20,520 \\
ATP 4 mM & 38,670 \\
" $+\mathrm{Mg} \mathrm{2mM}$ & 21,770 \\
\hline
\end{tabular}

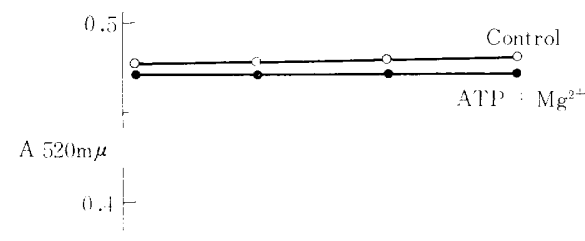

and the uptake of ${ }^{14} \mathrm{C}$-adrenaline was also found to be stimulated by the addition of ATP and $\mathrm{Mg}^{2+}$.

6) Structural changes in the granules caused by ATP and $\mathrm{Mg}^{2+}$

Experiments were carried out to see whether the structure of the granules changed when release of catecholamine was stimulated in the presence of ATP and $\mathrm{Mg}^{2+}$. To test this, changes in optical density of the granule suspension at $520 \mathrm{~m} / \mathrm{w}$ were examined. As shown in Fig. 6, there was little change in optical density on addition of ATP and $\mathrm{Mg}^{2+}$ 
when the granules were suspended in sucrose medium. However, it was found that the optical density of granules suspended in 154 mм NaCl-5 mм KCl solution decreased in the presence of ATP and $\mathrm{Mg}^{2+}$, as shown in Fig. 7. The decrease in optical density did not occur at $0^{\circ} \mathrm{C}$ even when ATP and $\mathrm{Mg}^{2+}$ were present in the medium. Moreover, neither ATP nor $\mathrm{Mg}^{2+}$ alone caused a decrease of optical density, as shown in Fig. 7.

\section{DISCUSSION}

The effect of ATP and $\mathrm{Mg}^{2+}$ on the release of catecholamine from adrenal medullary granules has been reported.

On the addition of ATP and $\mathrm{Mg}^{2+}$ there

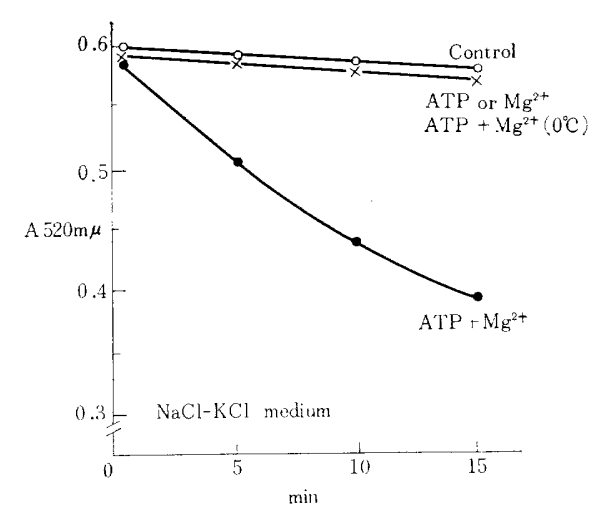

FIG. 7. Effect of ATP-Mg ${ }^{2+}$ on turbidity changes in catecholamine storage granules.

The medium consisted of $3.0 \mathrm{ml} 154$ mM NaCl-5 mM KCl, $80 \mathrm{~mm}$ Tris buffer (pH 7.3). ATP 4 mM, Mg 2 mM.

was no stimulation of the release of catecholamine from the granules when they were incubated in $0.3 \mathrm{~m}$ sucrose solution. However, it was of great interest that the rate of release of catecholamine from granules incubated in $154 \mathrm{~mm} \mathrm{NaCl}-5 \mathrm{~mm} \mathrm{KCl}$ solution was greatly stimulated by the addition of ATP together with $\mathrm{Mg}^{2+}$. Neither ATP nor $\mathrm{Mg}^{2+}$ alone had any effect on the release of catecholamine. The catecholamine release from the granules did not occur at $0^{\circ}-4 \mathrm{C}$ even in the presence of ATP and $\mathrm{Mg}^{2+}$. The stimulation of catecholamine release by ATP and $\mathrm{Mg}^{2+}$ was found to depend on the molar ratio of ATP to $\mathrm{Mg}^{2+}$ and the molar ratio of ATP to $\mathrm{Mg}^{2+}$ required for maximum release was thought to be about 2: 1. Moreover, ATP could not be replaced by the same concentration of ADP, AMP or adenosine.

These results are very interesting in relation to the finding that $\mathrm{Mg}^{2+}$-activated $\mathrm{ATP}$ ase is present in the membranes of granules of the adrenal medulla $(11,12)$. The granule preparation which was used in this work was shown to be practically free from mitochondria and to have $\mathrm{Mg}^{2+}$-activated ATPase activity. Therefore, it is suggested that $\mathrm{Mg}^{2+}$ activated ATPase in the granules of the adrenal medulla may be in some way linked with the mechanism of release of catecholamine from the granules.

Hillarp (11) has already suggested this because he found that relatively large amounts of ATP are present in the granules and ATP is released and broken down under conditions which cause release of catecholamine from the granules. Under "resting" conditions when there is no release of catecholamine from the granules, ATPase seems to be present in the granule membranes as a part of the structural protein. However, under various conditions which cause the release of catecholamine from the granules, the ATPase in the granule membrane seems to be activated in some unknown way enabling it to attack ATP within the granules and then catecholamine release from the granules may be initiated using energy derived from the splitting of intragranular ATP. In our experiments, how- 
ever, ATP and $\mathrm{Mg}^{2+}$ were added to the incubation medium. Therefore, although it is not possible in this paper to discuss the role of intragranular ATP in catecholamine release from the granules, it is suggested that the ATPase in the granule membrane is activated when ATP and $\mathrm{Mg}^{2+}$ are added to the incubation medium and that activation of this ATPase may contribute to the release of catecholamine.

Nothing definite is yet known about the mechanism by which the release of catecholamine is stimulated under conditions, such as addition of ATP and $\mathrm{Mg}^{2+}$, which activate ATPase in the membrane of the granules. However, it is very interesting that the optical density at $520 \mathrm{~m} \mu$ of granule suspensions decreased in the presence of ATP and $\mathrm{Mg}^{2+}$. This might indicate that ATP and $\mathrm{Mg}^{2+}$ might cause some structural changes in the granules, resulting in the rapid release of catecholamine from them. This suggestion was strongly supported by our recent findings (13) that the decrease of optical density of a granule suspension at $520 \mathrm{~m} \mu$ was also observed on addition of $\mathrm{Ca}^{2+}$, reserpine or oleate which are known to cause the release of catecholamine and ATP from the granules.

It is of interest to note that when the granules were incubated in sucrose solution the stimulation of catecholamine release by ATP and $\mathrm{Mg}^{2+}$ did not occur and structural changes in the granules, such as those described above, were also not observed in the presence of ATP and $\mathrm{Mg}^{2+}$. This might be attributable to the stabilizing properties of the suspension medium. This also supports the suggestion that the stimulatory effect of ATP and $\mathrm{Mg}^{2+}$ on catecholamine release is probably due to structural changes in the granules on addition of ATP and $\mathrm{Mg}^{2+}$. However, under these conditions, the uptake of ${ }^{14} \mathrm{C}$-adrenaline by the granules was found to be stimulated by the addition of ATP and $\mathrm{Mg}^{2+}$. This result supports the findings of Kirshner (1) and Carlsson et al. (2), suggesting that the $\mathrm{Mg}^{2+}$ activated ATPase in the granules is also related to the uptake of catecholamine into the granules. Stimulation of catecholamine uptake into the granules was also observed under conditions when catecholamine release from granules which were incubated in saline solution was stimulated by addition of ATP and $\mathrm{Mg}^{2+}$.

From these findings, it seems most probable that ATP and $\mathrm{Mg}^{2+}$ play an important role not only in the uptake of catecholamine into the granules, as previously reported by Kirshner (1) and Carlsson et al. (2), but also in its release. Moreover, it appears that when structural changes occur in the granules on addition of ATP and $\mathrm{Mg}^{2+}$, the release of catecholamine from the granules is greatly stimulated, while under conditions where structural changes of the granules do not occur on addition of ATP and $\mathrm{Mg}^{2+}$ only the uptake of catecholamine into the granules is stimulated.

With regard to the physiological significance of the actions of ATP and $\mathrm{Mg}^{2+}$, it is of interest to speculate that catecholamine is taken up and stored in the granules as an affect of the presence of ATP and $\mathrm{Mg}^{2+}$ under "resting" conditions, and when the medullary cell is stimulated resulting in release of catecholamine, ATP and $\mathrm{Mg}^{2+}$ promote the release of catecholamine from the granules. However, the physiological factors involved, and the mechanism of control of these actions of ATP and $\mathrm{Mg}^{2+}$ are still unknown.

Replacement of medium containing $154 \mathrm{~mm} \mathrm{NaCl}-5 \mathrm{~mm} \mathrm{KCl}$ by one containing 154 
mм KCl-5 mм NaCl did not affect the rate of $\mathrm{ATP}-\mathrm{Mg}^{2+}$ stimulated catecholamine release. The finding that the effect of ATP and $\mathrm{Mg}^{2+}$ was greatly diminished in the presence of inorganic phosphate was of interest in connection with the possibility that there may be a process regulating the $\mathrm{ATP}-\mathrm{Mg}^{2+}$ stimulated release of catecholamine from the granules. ADP or AMP did not affect the catecholamine release induced by ATP and $\mathrm{Mg}^{2+}$.

In previous papers, we and other workers have reported that $\mathrm{Ca}^{2+}$ may play an important role in the release of catecholamine from adrenal medullary cells or granules. Douglas and Rubin (14-16) have shown from perfusion experiments on the adrenal gland that acetylcholine or excess potassium stimulates the release of catecholamine by promoting an increased uptake of $\mathrm{Ca}^{2+}$ into the cells. Our previous work using slices of adrenal medulla supported their result and suggestion (17). Moreover, $\mathrm{Ca}^{2+}$ is known to have a direct action on isolated granules stimulating the release of catecholamine $(6,18,19)$. Therefore, it seems possible that $\mathrm{Ca}^{2+}$ takes part in the stimulatory action of ATP and $\mathrm{Mg}^{2+}$ on the release of catecholamine from the granules. However, $\mathrm{Ca}^{2+}$, which by itself caused the release of catecholamine from the granules, was shown to be inhibitory in the presence of ATP and $\mathrm{Mg}^{2+}$. Addition of a low concentration of $\mathrm{Ca}^{2+}\left(10^{-4}-10^{-6} \mathrm{M}\right)$ did not affect the stimulatory effect of ATP and $\mathrm{Mg}^{2+}$. Furthermore, the stimulatory effect of ATP and $\mathrm{Mg}^{2+}$ on the catecholamine release was observed even when the ATP preparation used had been passed through a Dowex 50 resin column to remove possible contamination with $\mathrm{Ca}^{2+}$, or when EDTA ( $1 \mathrm{~mm}$ ) was added to the incubation medium. It seems to be very difficult to remove a traces of $\mathrm{Ca}^{2+}$ from the medium, so more work is necessary to confirm the possibility that a low concentration of $\mathrm{Ca}^{2+}$ participates in this stimulatory effect of ATP and $\mathrm{Mg}^{2+}$. Moreover, since it is known that the granules contain relatively large amounts of $\mathrm{Ca}^{2+}$ (19-21), the role of this intragranular $\mathrm{Ca}^{2+}$ must also be considered in the stimulatory effect of ATP and $\mathrm{Mg}^{2+}$ on the release of catecholamine from the granules.

Recently, we have found that the activity of dopamine $\beta$-oxidase associated with the granule membrane was also stimulated under the same conditions which cause the release of catecholamine by ATP and $\mathrm{Mg}^{2+}(22)$. This finding is interesting for that it suggests the presence of mechanism coupling the release of catecholamine from the granules with the biosynthesis of catecholamine in the granules, and it is also suggestive in relation to the mechanism of catecholamine release from the granules.

\section{SUMMARY}

The release of catecholamine from adrenal medullary granules which were incubated in $154 \mathrm{~mm} \mathrm{NaCl}-5 \mathrm{~mm} \mathrm{KCl}$ solution was greatly stimulated by the addition of ATP together with $\mathrm{Mg}^{2+}$. Neither ATP nor $\mathrm{Mg}^{2+}$ alone had any effect on the release of catecholamine. Replacement of the medium containing $154 \mathrm{~mm} \mathrm{NaCl-5} \mathrm{mm}$ KCl by one containing 154 mu KCl-5 mM NaCl did not affect the rate of $\mathrm{ATP}-\mathrm{Mg}^{2+}$ stimulated catecholamine release. $\mathrm{Ca}^{2+}$, which by itself cause the release of catecholamine from the granules, was shown to be inhibitory in the presence of ATP and $\mathrm{Mg}^{2+}$. The molar ratio of $\mathrm{ATP}$ to $\mathrm{Mg}^{2+}$ required for maximum release is thought to be about $2: 1$. The uptake of ${ }^{14} \mathrm{C}$-adrenaline into the 
granules was also stimulated by ATP and $\mathrm{Mg}^{2+}$ under these conditions.

The decrease of optical density at $520 \mathrm{~m} \mu$ in a granule suspension was accelerated by the addition of ATP and $\mathrm{Mg}^{2+}$. Therefore it was suggested that ATP and $\mathrm{Mg}^{2+}$ caused some structural changes in the granules, probably through the ATPase associated with the membranes of the granules, leading to the release of catecholamine from the granules.

This work was partly supported by a grant from the Japanese Wakesman Foundation.

\section{REFERENGES}

1) Kirshner, N.: J. boil. Chem. 237, 2311 (1962)

2) Carlsson, A., Hillarp, N.Å. and Waldeck, B.: Acta physiol. scand. 59, (suppl. 251) 1 (1963)

3) Euler, U.S.v. ANd Lishajko, F.: Ibid. 59, 454 (1963)

4) StJ̈̈rne, L.: Ibid. 62, (suppl. 228) 1 (1964)

5) Oka, M., Ohuchi, T., Yoshida, H. and Imaizumi, R.: Biochim. biophys. Acta 97, 170 (1965)

6) Oka, M., Ohuchi, T., Yoshida, H. and Imaizumi, R.: Life Sci. 5, 433 (1966)

7) Hillarp, N.Å.: Acta physiol. scand. 43, 82 (1958)

8) Kirshner, N.: J. biol. Chem. 237, 2311 (1962)

9) Oka, M., Ohuchi, T., Yoshida, H. and Imaizumi, R.: Life Sci. 5, 427 (1966)

10) Weil-Malherbe, H. and Bone, A.D.: Biochem. J. 51, 311 (1952)

11) Hillarp, N.Å.: Acta physiol. scand. 42, 144 (1958)

12) Banks, P.: Biochem. J. 95, 490 (1965)

13) Oka, M., Ohuchi, T., Yoshida, H. and Imaizumi, R.: Life Sci. 6, 467 (1967)

14) Douglas, W.W. and Rubin, R.P.: J. Physiol. 159, 40 (1961)

15) Douglas, W.W. and Rubin, R.P.: Ibid. 167, 288 (1963)

16) Douglas, W.W. And Poisner, A.M.: Ibid. 162, 385 (1962)

17) Oka, M., Ohuchi, T., Yoshida, H. and Imaizumi, R.: This Journal 15, 348 (1965)

18) Schümann, H.J.: Arch. exp. Path. Pharmak. 244, 466 (1963)

19) Philippu, A. And SchÜmann, H.J.: Ibid. 252, 339 (1966)

20) Schümann, H.J.: Pharmar. Rev. 18, 433 (1966)

21) Borowitz, J.L., Fuwa, K. And Weiner, N.: Nature, Lond. 205, 42 (1965)

22) Ока, М., Онuchi, T., Yoshida, H. and Imaizumi, R.: unpublished 